\title{
A Construção do Sítio Ciência na Comunidade: Antecedentes, Fundamentos, Narrativas Híbridas e Conteúdo Epistemológico
}

\section{The Construction of the Science in the Community website: Antecedents, Foundations, Hybrid Narratives and Epistemological Content}

\section{Paulo César Pinheiro ${ }^{\circledR}$ Brasil}

$\mathrm{O}$ artigo apresenta os antecedentes e fundamentos que levaram à construção do sítio Ciência na Comunidade, um ambiente criado recentemente na internet para compartilhar experiências de interação com saberes culturais locais. Inicialmente descreve a proposta de inserção de saberes populares na educação em química e ciências no Brasil e ênfases correlacionadas observadas na literatura internacional, destacando a formação docente, seus problemas e um debate envolvendo o conhecimento indígena e a natureza da ciência. Em seguida, apresenta resultados de estudos empíricos em salas de aula e a convergência com a literatura para oferecer conteúdo epistemológico para professores com base em narrativas híbridas. Como fundamentos, apresenta os conceitos de hibridização/hibridismo, narrativa e a dimensão da análise epistemológica efetuada. Os procedimentos metodológicos destacam: a construção de enunciados híbridos e sua arquitetura dialógica, semântica, sintática e iterativa; o desenvolvimento de atividades com linguagens, imagens e afirmações da literatura e a direção de analisar e organizar o conteúdo epistemológico em cinco eixos/textos: os saberes e seus contextos, linguagens, práticas, teorias e representações. Esse conjunto de recursos é destinado aos que querem aprofundar seus conhecimentos sobre as relações entre saberes culturais locais e científicos, destacando a mistura de linguagens como forma de comunicar os conteúdos, a ausência de voz autoritária nesta construção e a indissociável relação entre conhecimento e contexto para as tarefas de representação e comparação epistemológica dos saberes.

Palavras-chave: saberes locais; narrativas híbridas; conteúdo epistemológico.

The article presents the antecedents and foundations which led to the construction of the website Science in the Community, a virtual environment just created to share experiences on local cultural knowledge using the internet. Initially, it describes the proposal of folk knowledge insertion into chemistry and science education in Brazil and other related emphases in the international literature, highlighting teachers' education, its problems 
and a debate involving indigenous knowledge and the nature of science. Next, it describes the results of empirical inquiries in classrooms and the convergence with literature to offer epistemological content for teachers based on hybrid narratives. As a theoretical background, it presents the concepts of hybridization/hybridism, of narrative and the epistemological dimension of the analysis carried out. The methodological procedures emphasize the construction of hybrid utterances and their dialogic, semantic, syntactic and iterative architecture; the development of activities on languages, images, assertions from literature, and the way the epistemological content was analyzed and organized according to five axes/texts: the knowledges and their contexts, languages, practices, theories, and representations. This set of resources is for those who want to deepen their knowledge on local and scientific knowledge relationships, underlining the mixing of languages as a way to communicate both contents, the absence of authoritarian voice on such a construction and the inextricable link between knowledge and context for the task of knowledge's representation and epistemological comparison.

Keywords: local knowledge; hybrid narratives; epistemological content.

\section{Introdução}

A palavra comunidade normalmente evoca sentimentos de familiaridade, conforto e segurança. Pode ter dois significados: referir-se a um local geográfico onde as pessoas vivem e se conhecem ou a um grupo de pessoas interagindo/colaborando/se comunicando com interesses e ações comuns, independente de estarem no mesmo local. Os verbos pertencer, participar e compartilhar resumem esses significados, mas também não deixam de ser excludentes, já que põem de lado pessoas de outros locais ou que não têm os mesmos interesses. De modo geral, as comunidades são plurais, internamente heterogêneas e em muitas delas há saberes, práticas e atitudes relacionadas à ciência e aos currículos escolares. Uma comunidade importante nesse contexto é a "comunidade racional" da ciência. A escola funciona como sua extensão, já que é nela que se começa a ensinar seus conhecimentos e normas, embora isso nem sempre ocorra satisfatoriamente e possa se tornar um problema quando os estudantes não compreendem ou compartilham seus saberes e valores. Uma possibilidade é estudar a ciência localmente ou associá-la ao que existe em suas comunidades ou meios sociais. O sítio Ciência na Comunidade é um ambiente recentemente criado na internet visando compartilhar experiências nesta direção. O presente artigo apresenta os antecedentes literários, empíricos e fundamentos que levaram à construção de um conjunto inicial de recursos que conjuga narrativas híbridas, atividades na tela do computador e conteúdo epistemológico. O objetivo é oferecer subsídios para compreensão desta construção e apontar suas contribuições, especialmente o tipo de inter-relação dialogizada estabelecido entre as culturas da comunidade e da ciência e a natureza da análise epistemológica realizada. 


\section{Perspectivas nacionais}

Em uma análise da história do ensino de ciências no Brasil, Nascimento, Fernandes e Mendonça (2010) mencionaram os movimentos atuais da educação científico-tecnológica e da alfabetização científica para todos e que esses pressupõem amplas relações entre ciência, tecnologia, sociedade e meio ambiente. Eles também consideraram a inserção da ciência na cultura como forma de sua compreensão por todos os cidadãos. As atuais Diretrizes Curriculares Nacionais para a Educação Básica (Ministério da Educação, 2013) enfatizam o tratamento da cultura brasileira e a vinculação entre a educação escolar e a sociedade. Ao sugerir o acolhimento dos diferentes saberes e manifestações culturais existentes no país, essas diretrizes adotam essencialmente uma perspectiva curricular multicultural, compreendendo com isso a possibilidade de minimizar o fracasso escolar. Sugerem a interação entre os conhecimentos disciplinares e das culturas populares, de modo a valorizá-las, analisá-las e compreendê-las na escola. Para o ensino médio, em particular, as diretrizes apontam para a dependência entre as dimensões científica-tecnológica-cultural e propõem a integração entre trabalho, ciência, tecnologia e cultura na base do desenvolvimento curricular.

Um dos marcos de aproximação com os saberes populares na educação em química no Brasil foi o livro A Educação no Ensino de Química (Chassot, 1990), particularmente o capítulo Procurando resgatar a química nos saberes populares, no qual foram tecidas considerações sobre "uma linha de trabalho relativamente nova na área de Educação Química" (p. 103). O tema foi retomado posteriormente em dois capítulos de um livro seguinte (Chassot, 2001): Procurando resgatar a ciência nos saberes populares; Procurando um ensino de ciências fora da sala de aula. Nesses três textos encontramos pressupostos, fundamentos, orientações metodológicas e exemplos de saberes e práticas populares com possibilidades de estudo em aulas de ciências. Um pressuposto dado como importante é "trabalhar criticamente a ciência do cientista, a ciência da escola e a ciência popular", as quais possuem características próprias, interações, "descréditos múltiplos", "resistências e incompreensões". Em seus escritos, Chassot critica a escola (e a Academia) por "virar as costas para o saber popular", desprezando-o "no cortejar que faz ao saber institucionalizado" (Chassot, 1990, p. 104, 105). Contrariamente, propõe valorizar e respeitar os saberes populares, mas observa que seus conteúdos podem não fazer parte dos currículos e que nem sempre o conhecimento científico correlacionado encontra-se disponível ou exige pesquisa. É indubitável, no entanto, que essa proposta demanda uma pedagogia diferenciada:

A proposta que se defende implica na necessidade de resgatar a Química que está inserida na realidade física e social vivenciada pelos alunos (ou em outras realidades) e analisar com eles, de forma dialógica, os diferentes significados atribuídos e as diferentes formas de construção do conhecimento. (Chassot, 1990, p. 104)

As publicações de Chassot marcaram o início de uma perspectiva no Brasil que não só sensibilizou como também conduziu à sua ampla aceitação por pesquisadores 
e educadores da área de educação em ciências. Em outras palavras, ainda não foi questionada ou contestada, mas, ao contrário, vem sendo reforçada. Na revista Química Nova na Escola, por exemplo, há sete artigos relacionados a essa temática que fazem referência às ideias iniciais de Chassot. Uma dessas publicações é do próprio autor (Chassot, 2008a), enquanto as demais foram produzidas por outros: Francisco Junior, Yamashita, e Martines (2013); Gondim e Mol (2008), Leal e Moita Neto (2013), Resende, Castro e Pinheiro (2010), Silva, Aguiar e Medeiros (2000); Venquiaruto, Dallago, Vanzeto, e Pino (2011). Chassot (2008b, p. 198) também se referiu aos saberes populares como "saberes primevos" ou "ciência primeva", apontando suas relações com saberes iniciais ou dos primeiros tempos. Na obra deste autor, observa-se nítida conotação histórica.

A Revista Brasileira de Pesquisa em Educação em Ciências (RBPEC) também vem apresentando publicações em direção semelhante, tendo sido identificados quatro artigos de autores brasileiros: Cavaglier e Messeder (2014), Medeiros e Medeiros (2002), Silva (2003) e Silveira e Mortimer (2011).Os primeiros mostraram como o tema das plantas medicinas pode ser inserido na Educação de Jovens e Adultos partindo dos saberes dos alunos, com proposição de módulos de ensino interdisciplinares que integram textos, tabelas, vídeos e experimentos. Os dois autores seguintes analisaram o imaginário sobre raios de um grupo de indivíduos de uma comunidade rural e apontaram possibilidades de exploração dos conteúdos escolares associados. O terceiro investigou o conceito de proporção na produção de argamassas entre trabalhadores da construção civil e os dois últimos observaram convergências e divergências entre os modos de pensamento indígena e científico sobre transformações químicas.

Uma característica geral das publicações nessas duas revistas é a interação de pesquisadores com pessoas simples da comunidade ou grupos culturais específicos utilizando referenciais teóricos e metodológicos diversificados para apreender seus saberes, explicá-los cientificamente, identificar conteúdos escolares e propor materiais didáticos. Há poucos estudos voltados para a formação docente. Um relato envolvendo experiência dessa natureza foi descrito por Chassot (2008a) em um curso de pedagogia, cuja base foi a interação de acadêmicos com a comunidade, concomitante à discussão das etapas de desenvolvimento de uma pesquisa, ou seja, a formação se deu nos moldes de uma pesquisa acadêmica conduzida em um contexto de uma aprendizagem sobre a mesma (Ver também Chassot, 2008b).

Em uma investigação sobre o "estado da arte" da temática dos saberes populares na pesquisa em educação em ciências no Brasil, Xavier e Flôr (2015) também mencionaram a falta de abordagens epistemológicas na literatura, o que é uma tendência mais comum nos artigos publicados na RBPEC. Outra lacuna é a ausência de investigações de experiências realizadas em salas de aula e um problema é a tendência de alguns autores em interpretar a frase "saberes primevos fazendo-se saberes escolares" (Chassot, 2008b, p. 197) de forma a realizar uma espécie de antropofagia seguida pela regurgitação dos saberes como experimentos de laboratório, os quais, embora interessantes e criativos, geralmente resultam na modificação da matriz original de conhecimento em sua 
conversão para a ciência escolar.

Também devem ser mencionadas as experiências no campo da etnomatemática ( $\mathrm{D}^{\prime}$ Ambrosio, 1998), que tiveram início no Brasil e depois se espalharam pelo mundo (Etnomatemática, 2001), em Etnoastronomia (2006) e Etnobiologia (Baptista, \& El Hani, 2009; Baptista, Vargas-Clavijo, \& Neto, 2014), a qual recentemente vem desenvolvendo trabalhos em educação. Sobre Etnoquímica, Francisco (2004) propôs um conjunto de definições para designar uma área ou programa de pesquisa situado entre a antropologia cultural e a química que busca analisar os saberes, práticas, técnicas e tecnologias relativas ao uso e transformação dos materiais por diferentes grupos culturais de Moçambique, com implicações metodológicas e epistemológicas para o ensino de química e a formação de professores. Considerando essas e outras publicações, cabe questionar em que medida elas vêm sendo utilizadas e discutidas nos cursos de licenciatura do país, se vêm sensibilizando professores e se os têm levado a atuar ou, ao menos, experimentar ensinar nessa perspectiva. Como essas propostas e ideias são vistas pelos professores? Existem dificuldades de implementação? Quais? Como está se dando a formação docente no Brasil nessa perspectiva e quais são as suas contribuições para a educação em ciências?

\section{Ênfases da literatura internacional}

Não é comum observar o correspondente em inglês para "saberes populares" na forma de folk ou popular knowledge em periódicos internacionais da educação em ciências; essa denominação foi observada somente em Pomeroy (1994) e a terminologia normalmente empregada engloba expressões como: primordial science and technology, primitivescience, native technology, indigenous resources, indigenous knowledge, indigenous science, traditional knowledge, traditional ecological knowledge e local technology. Essas denominações se referem: (a) à existência de ciência e atitudes científicas entre povos nativos (Malinowski, 1948 citado em Maddock, 1981); (b) à percepção racional da realidade por grupos culturais específicos que é dependente da cultura e transmitida oralmente ao longo de gerações (Ogawa, 1995) e pode ser encontrada inteira ou na forma de traços nas vidas cotidianas de seus herdeiros (George, 1999); (c) às culturas indígenas expansionistas (Astecas, Maias e Mongóis, por exemplo) e aos povos de residência de longo tempo (aborígenes da África, Américas, Ásia, Europa e Nova Zelândia) (Snively, \& Corsiglia, 2001); (d) aos saberes que pertencem naturalmente a um grupo de pessoas de uma comunidade particular (George, 1992); e) ao "conhecimento local que é único de uma dada cultura ou sociedade e que contrasta com o sistema internacional de conhecimento que é gerado através da rede global de universidades e institutos de pesquisa" (Warren, Slikkerveer, \& Brokensha, 1995, p. xv).

As expressões mais frequentes observadas na literatura internacional são indigenous science (ciência indígena), indigenous knowledge (conhecimento indígena) e traditional ecological knowledge (conhecimento ecológico tradicional). Embora essa última remeta a uma disciplina científica, denota um conhecimento que não tem origem nas instituições oficiais da ciência. A expressão local technology (tecnologia local) foi 
empregada por Haden (1973) para nomear o domínio da tecnologia de produção de ferro metálico por anciãos da tribo Okebu, em Uganda, no contexto de uma experiência educacional pioneira realizada no ensino de química e compreende um relato raro de experiência em sala de aula. Além dessas denominações, Antweiler (1998) apontou outras, algumas características e os indivíduos associados: endógenos, sustentáveis, autóctones, das pessoas ou do povo, orais, culturais, étnicos, etnociência, culturalmente específicos, cotidianos, ciência do concreto, práticos, mundanos, informais, do dia a dia, experiencial, dos agricultores ou dos camponeses. $\mathrm{O}$ uso de uma ou outra denominação tem as suas razões: "conhecimento indígena" e "conhecimento ecológico tradicional", por exemplo, foram consideradas por McKinley (2007) como tendo uma conotação política no cenário internacional, o que também sugere ser o caso dos "saberes populares" no Brasil, visto a inclusão dos mesmos nos currículos ter sido associada a uma função política da escola (Chassot, 1990).

Os recursos baseados na cultura e no local (place-based, culture-based science education) são objetos de uma área de pesquisa emergente nos Estados Unidos que se volta ao desenvolvimento de conhecimento pedagógico de conteúdo para professores de ciências (Chinn, 2012). Esta área tem influência do movimento que ficou conhecido por Educação Progressiva nesse país e que teve John Dewey como precursor em sua crítica ao desvinculo entre a ciência e a vida dos estudantes das escolas americanas do final do século XIX. De modo semelhante, Adams (2012) definiu Community Science (Comunidade Ciência) como um constructo para ensinar e aprender fundado no estabelecimento de conexões entre o conhecimento que existe na comunidade e a ciência aprendida na escola. Essa autora reuniu experiências internacionais de ensino baseadas em uma pedagogia dialética responsiva à diversidade da cultura e à polissemia dos processos de significação das experiências envolvendo escola e comunidade, incluindo analisar como as pessoas veem e utilizam a ciência para tomar decisões no dia a dia e compreender os saberes que não usam os mesmos termos e entendimentos, mas que podem ser usados para promover aprendizagem. Os textos de Chinn (2012) e Adams (2012) mostram experiências educacionais e de formação docente baseadas na cultura e na interação com saberes de comunidades locais com implicações para a transformação social e o desenvolvimento sustentável. Assim, de modo geral, há um número relativamente elevado de publicações nos periódicos internacionais direcionadas às interações com outros modos de conhecer na educação em ciências, especialmente o conhecimento indígena. Frentes de pesquisa vem se consolidando e apresentam propostas, relatos e redes de experiências para formação de professores. Há referenciais teóricos em comum, as abordagens tendem a ser mais teóricas e filosóficas e também é pouco comum encontrar relatos de experiência em sala de aula.

\section{0 acirrado debate entre universalistas e multiculturalistas}

O conhecimento indígena esteve no cerne de um debate estabelecido na revista Science Education, logo que apareceram os primeiros artigos sobre a educação 
multicultural em ciências, antes e após a edição especial sobre o tema no ano de 2001. Esse debate foi caracterizado como um confronto "feroz" (que abalou as fundações da educação em ciências (Mckinley, \& Stewart, 2012; Van Eijck, \& Roth, 2007), com pelo menos 20 publicações incluindo artigos, críticas e contra respostas. Algumas são citadas ao longo deste texto e outras podem ser exemplificadas em: Atwater e Riley (1993), Brown-Acquaye (2001), Hodson (1993), McKinley (2001), Montellano (2001) e Stanley e Brickhouse (2001a; 2001b). Nas discussões, observam-se duas epistemologias distintas e incompatíveis constituídas pela oposição entre universalistas e multiculturalistas, as quais podem ser resumidas do seguinte modo:

Para a maior parte, a educação em ciências permaneceu imune à crítica multiculturalista considerando o apelo à epistemologia universalista: que a cultura, gênero, raça, etnia ou orientação sexual do conhecedor são irrelevantes para o conhecimento científico. É o mundo natural que em última análise julga ou atesta o mesmo, não o inverso (Matthews, 1993). Dito de outro modo, a realidade do mundo material é indiferente às qualidades pessoais dos investigadores. Enquanto for amplamente reconhecido que os cientistas são individualmente tendenciosos, a longo prazo serão considerados os processos de revisão por pares e a metodologia científica como meios adequados para correção de tais distorções.

[...] A tradição universalista vem sendo desafiada pelos filósofos da ciência, acadêmicos feministas e, mais recentemente, pelos multiculturalistas. Os multiculturalistas, por exemplo, vêm apontando que as abordagens não-Ocidentais para a ciência não são incluídas no currículo atual. A resposta universalista reconhece a contribuição de outras culturas para a ciência Ocidental, porém nega que os sistemas de conhecimento de tais culturas sejam entendidos como 'ciência'. (Stanley, \& Brickhouse, 1994, p. 388, 389)

O ponto nevrálgico das discussões foi o status do conhecimento ecológico tradicional, que não é oficialmente reconhecido como ciência. Um estopim foi o artigo de Snively e Corsiglia (2001), particularmente por afirmarem o contrário, justificando, assim, a inclusão desse conhecimento nos currículos. Os universalistas, por sua vez, não reconheceram tal conhecimento como sendo "científico", porque esse adjetivo é usado por eles para denominar um conhecimento que transcende contextos locais e é válido em toda parte. Em contraste, os multiculturalistas insistiram na existência de diferentes formas de ciência. Assim, ficaram de um lado "os universalistas", defensores de uma visão universal da ciência e de sua superioridade epistemológica e, de outro, ficaram "os multiculturalistas", críticos dessa visão e de sua postura de exclusividade/exclusão refletida nos currículos. Entretanto, os multiculturalistas não são os únicos que se opõem aos universalistas. Desde a década de 1990 vem ocorrendo um movimento contrário às visões imperialistas do Ocidente em relação às outras formas de conhecimento, influenciado em grande parte pelos estudos sociais da ciência. O multiculturalismo, o pós-colonialismo e o pós-modernismo estão entre as perspectivas epistemológicas de resistência (Cobern \& Loving, 2001).

As discussões em Science Education envolveram assuntos diversos, tais como: 
o lugar e o papel do conhecimento indígena nos currículos, se tal conhecimento pode ser considerado ciência ou forma distinta e igualmente válida de conhecimento, epistemologia da ciência e do conhecimento indígena, universalidade da ciência, contribuições do conhecimento indígena e outros, destacando-se a necessidade de definir termos-chave, tais como "ciência", "ciência ocidental", "ciência indígena" e "ciência escolar". No Brasil, parece que não houve oposição quanto a denominar os "saberes populares" de "ciência popular" ou "ciência primeva" (Chassot, 1990, p. 104; 2008b, p. 198). No periódico estadunidense as posições foram antagônicas e o problema maior foi atribuir o status de ciência ao conhecimento ecológico tradicional. Por isso, frente às possibilidades de inclusão de outros modos de conhecer nos currículos, alguns autores (Cobern, \& Loving, 2001) definiram características para distinguir a ciência na educação básica.

A educação multicultural em ciências é mais conhecida nos países que foram originalmente colonizados por Europeus e cuja população convive com minorias indígenas, como ocorre nos Estados Unidos, Austrália, Canadá e Nova Zelândia (Aotearoa). Nesses países, as culturas indígenas sofreram um "culticídio" ou desintegração na interação com a ciência e a educação colonial, as quais contribuíram para a destruição total ou parcial de seus sistemas de conhecimento. Frente a isso, algumas perspectivas vêm procurando transpor a tendência eurocêntrica, imperialista, racista e etnocêntrica dos currículos (Cobern, \& Loving, 2001, p. 53; Van Eijck, \& Roth, 2007, p. 929). Em relação ao conhecimento ecológico tradicional, destaca-se a posição de Cobern e Loving (2001), que preferiram não o considerar como ciência, mas como outro modo de conhecer que tem seu próprio valor e mérito. Segundo eles, isso não diminui o status desse conhecimento e nem torna injustificável a sua inserção nos currículos. Eles sugeriram valorizar o conhecimento em suas múltiplas formas e origens nos currículos, alegando que isso pode contribuir para que os estudantes percebam que "alguns dos insights da ciência podem ser alcançados por outros percursos epistemológicos", bem como "o que a ciência pode fazer que outros domínios não podem" (Cobern, \& Loving, 2001, p. 63). Nessa mesma direção, Stanley e Brickhouse (2001b, p. 46) mencionaram que o "melhor" que a educação multicultural em ciências pode fazer é "introduzir os estudantes a novos modos de pensamento sobre o mundo natural" e "compreender alguns dos princípios fundamentais dos modos Ocidentais de pensamento". O que se destaca nessas posições, no debate em Science Education e em outros autores (Mckinley, \& Stewart, 2012) são as implicações do conhecimento indígena para a natureza da ciência.

\section{A formação docente e seus problemas}

No campo da educação indígena em ciências, uma tendência é ver o professor de ciências como "agente" ou "mediador cultural" (Mckinley, \& Stewart, 2012, p. 546), mas a formação docente tem os seus problemas:

A educação científica indígena e a pesquisa ocorrem em um nexo complexo de relações filosóficas, históricas, psicológicas, sociológicas e políticas que tendem a soterrar o 
empreendimento. Infelizmente, esses entendimentos não são apropriados pela maioria dos professores de ciências, autoridades educacionais ou acadêmicos formadores. É sobre este último grupo, como argumenta Graham Smith (1995), que a responsabilidade primária recai para iniciar o trabalho no sentido de melhorar essa falta, apesar de suas limitações. (Mckinley, \& Stewart, 2012 p. 541)

As experiências nesse campo provêm principalmente de países como Canadá, Nova Zelândia, Austrália, Estados Unidos, África e Japão. Em alguns, os currículos oficiais propõem, inclusive, a incorporação do conhecimento indígena em escolas não indígenas, como ocorre na Nova Zelândia (Mckinley, \& Stewart, 2012) e no Canadá (Snively, \& Corsiglia, 2005), por exemplo. Todavia, a pesquisa realizada por McKinley e Stewart (2012) mostrou que os professores de ciências neozelandeses vêm abordando o conhecimento indígena de modo superficial nas aulas e sem conexão com seus contextos culturais, históricos e sociopolíticos, adquirindo a forma de "caricatura". Concluíram que esse conhecimento está "fora de lugar" e apontaram algumas razões: a predominância de uma visão universalista de ciência entre os professores; o propósito das aulas é ensinar ciências; os professores são formados nessa direção e, por essa razão, não são os profissionais adequados para abordar o conhecimento indígena na escola. Essa postura surpreende na medida em que se opõe ao que vinha sendo defendido por muitos no debate estabelecido nos artigos publicados em Science Education. De outro lado, é curioso observar o descompasso entre o ensino e a pesquisa em um país que, conforme menção das autoras, é líder mundial nas pesquisas sobre a educação indígena em ciências. Essa pesquisa, no entanto, chama atenção para um aspecto importante da inserção de outros modos de conhecer nos currículos: a forma como os saberes são representados ou a imagem que adquirem ao serem (re)apresentados aos alunos. June George (1992) percebeu isso ao dizer que a reconstituição dos saberes nativos exige uma responsabilidade especial de modo a corresponder factualmente à realidade, mas não atribuiu essa tarefa aos professores: "A construção de tal base de dados é um processo que consome tempo e não deve haver expectativa de que os professores de ciências façam isso por eles mesmos. Os pesquisadores do ensino de ciências podem desempenhar um papel aqui" (p. 107).

Porém, mesmo que os pesquisadores do ensino de ciências ajudem nessa tarefa, a representação dos saberes é sempre problemática, limitada, incompleta e influenciada por quem os representa (Mckinley, \& Stewart, 2012). Adams (2012, p. 1172) acredita que os professores podem desenvolver iniciativas e criar "hábitos mentais" para trazer a cultura da comunidade para a sala de aula, mas admitiu ser necessário adquirirem conhecimento sobre as culturas e linguagens dos alunos, o "trabalho das culturas" que existem na comunidade e os conteúdos de ciências. No Handbook for culturally responsive science curriculum (Manual do currículo de ciências culturalmente responsivo) publicado no estado do Alaska/EUA, o qual vem se destacando mundialmente por seus avanços educacionais nessa direção, Stephens (2003) previu os seguintes obstáculos: o professor pode não dispor de conhecimento ou entendimento sobre o conhecimento cultural; 
os especialistas culturais (pessoas da comunidade) podem não estar familiarizados, sentir desconforto ou hesitar trabalhar na escola; os livros didáticos de ciências pouco ajudam no desenvolvimento de atividades localmente relevantes; pode não haver apoio administrativo ou da comunidade e é preciso dispor de tempo e compromisso. Face às dificuldades de os professores compreenderem ou aceitarem trabalhar nessa perspectiva, Chinn (2007) adotou o uso de "metodologias descolonizadoras" - estratégias de comunicação e questionamento crítico das perspectivas dominantes na escola, na vida e na sociedade (p. 1252, 1253).

Uma justificativa para a inserção de "perspectivas e práticas discursivas marginalizadas" na educação em ciências foi expressa por Slaton e Barton (2012, p. 517) como uma atitude de respeito. Essas autoras observam que a educação em ciências tem poder para legitimar saberes e discursos, mas para dar sentido a essas diferentes perspectivas sugeriram a desconstrução do poder e da autoridade dominante nas aulas e promover discursos híbridos - criar um "terceiro espaço" de mudança cultural, social e epistemológica, no qual saberes e discursos competitivos são trazidos para conversação e servem também para contestar e remodelar as formas tradicionais de letramento. Mas, o que significa a palavra "desconstrução" nessa perspectiva? Parece-nos que significa deslocar o conhecimento e a autoridade dominante de suas posições hierarquicamente dominantes, sem negá-los, mas mantendo-os sob apagamento em alguns momentos segundo um jogo de desfazer/preservar suas posições.

\section{Antecedentes empíricos}

O que motivou inicialmente a investigação de saberes e práticas das comunidades locais foi o problema do distanciamento entre o ensino de ciências e o seu entorno cultural (Pinheiro et al., 1985). Assim, iniciei estudos enquanto estudante de graduação em Química e os estendi depois na pós-graduação e na orientação de acadêmicos em projetos de iniciação científica, extensão universitária e dissertações de mestrado. Um dos objetivos sempre foi elucidar os saberes por meio do conhecimento científico. Nesse sentido, ocorreram pesquisas em livros técnicos e científicos e em laboratórios e, para as interações com a comunidade, o referencial inicial foi o da pesquisa participante (Brandão, 1982; 1987).

Em certo momento, as experiências escolares promovidas transitaram da interação face a face (direta) entre alunos e a comunidade para o uso de instrumentos mediadores na forma de textos, vídeos e sistemas hipermídia. Isso ocorreu devido à dificuldade de compatibilizar tempos e espaços e porque alguns indivíduos da comunidade não se sentiram à vontade para trabalhar diretamente com os estudantes. O problema então passou a ser o transporte dos saberes para a sala de aula usando esses meios, o que Silva (2003, p. 80) chamou de "transferência entre contextos" e considerou como um dos "grandes problemas educacionais a serem confrontados por pesquisadores e educadores". A opção foi seguir recomendações da etnografia de saberes, técnicas e práticas (D’Olne Campos, 2002), da etnobiologia (Posey, 1986), da etnografia da antropologia cultural 
(Clifford, 1998; Geertz, 1973; Grills, 1998; Malinowski, 1984) e suas derivações na forma de foto-etnografias (Accutti, 2006; Lévi-Straus, 1994) e filmes etnográficos (France, 2000). A análise do discurso também se tornou uma ferramenta importante por permitir identificar os contextos associados às práticas da comunidade - a "teia de relações" (Foucault, 1986), e incorporá-los às descrições etnográficas. A percepção das linguagens sociais da comunidade e da ciência contendo gêneros de discurso específicos (Bakhtin, 1986), por sua vez, configurou uma base para compreender as relações semânticas e promover "travessias entre fronteiras culturais" conforme a proposta pedagógica de Aikenhead (1996).

No momento atual, as experiências reúnem um conjunto de cinco saberes tradicionais relacionados à produção de artefatos culturais específicos: o sabão de cinzas, o vinho de laranja, o doce de leite, o polvilho azedo e os tijolos de uma olaria artesanal (Pinheiro, Felício, \& Monteiro, 1987; Pinheiro, \& Felício, 1988; Pinheiro, \& Giordan, 2008; Pinheiro, \& Giordan, 2010; Pinheiro, \& Gomes, 2000; Resende, Castro, \& Pinheiro, 2010). Nas experiências escolares, o que se destacou foi o elevado nível de interesse e engajamento do alunado. Quando os estudantes foram envolvidos em interações diretas com a comunidade, inicialmente interagiram com as práticas em seus locais de desenvolvimento e depois exploraram os conteúdos no nível fundamental, realizando experimentos e participando de atividades em aulas dialogadas. As experiências no ensino médio foram aquelas mediadas por textos, vídeos e hipermídias. $\mathrm{Na}$ maior parte dos casos os professores ajudaram no planejamento e cederam suas aulas para o desenvolvimento das atividades. Como a produção de mídias digitais (vídeo-DVDs e hipermídias) vem sendo enfatizada mais recentemente, elas foram disponibilizadas aos professores para identificar como e se eles as utilizam em suas aulas. Numa primeira experiência, uma professora analisou a hipermídia sobre o sabão de cinzas e considerou a possibilidade de inseri-la em suas aulas de química, mas disse que precisaria de tempo para estudar os conteúdos e se preparar. Nessa mídia, os saberes da comunidade são descritos e acompanhados de perguntas para a interpretação dos alunos. Como isso não exigiu a participação da professora, combinamos que os trabalhos fossem iniciados com a exploração autônoma da hipermídia pelos alunos reunidos em grupos. Antes do início das atividades, porém, já havia se tornado evidente a necessidade de oferecer um suporte ao trabalho pedagógico da professora, o que foi ocorrendo na forma de conversas, sugestões, indicação de textos para leitura e com oferecimento de uma segunda hipermídia de apoio (Pinheiro, 2007).

Ao final das atividades, a professora revelou qual foi a sua maior dificuldade nas aulas: saber como lidar com as diferentes visões e linguagens. Assim que os alunos concluíram a exploração da primeira hipermídia e de suas questões, ela realizou experimentos, elaborou explicações e explorou a segunda mídia, na qual os conteúdos foram organizados em páginas eletrônicas de acordo com cada pergunta formulada juntamente com as respostas dos grupos de alunos. A professora observou que as aulas envolveram três linguagens: a da comunidade, a da ciência e a da didática, cuja base, 
segundo ela, foi o estabelecimento de relações. Ela dedicou a maior parte das aulas à exploração dos conteúdos (perguntas/respostas) e em alguns momentos procurou caracterizar os saberes. Ela chamou de "saber popular" o saber retratado na hipermídia, disse que era um "conhecimento prático" decorrente de processos de "tentativa e erro", que não tinha "rigor científico" e "nem maiores explicações". Reconheceu que isso não era um problema, na medida que obteve sucesso "com o tempo". Em relação à "visão da Química", enfatizou ter "toda uma explicação", "um saber sistematizado, elaborado, organizado". Essa "visão" foi associada ao que é ensinado na escola e embora o conhecimento da comunidade tivesse outro percurso, apresentava coerência com o conhecimento científico. Como professora de química, defendeu a relevância dessa ciência como fonte de explicações confiáveis, mas também considerou as "duas visões" como sendo válidas. Todavia, ela se surpreendeu ao ver a facilidade com que os alunos se apropriaram (no sentido dado por Wertsch, 1993) dos saberes e da linguagem da comunidade e ficou incomodada pela maioria não se basear no conhecimento químico para construir suas respostas às perguntas propostas. Por isso, questionou-os e quis saber onde iriam situar os "seus" conhecimentos a partir daquelas aulas.

A princípio não houve nenhum problema na abordagem da professora, considerando que essa foi sua primeira experiência desse tipo. Oferecer suporte na forma de conhecimento dos conteúdos foi importante porque economizou seu tempo, deu-lhe segurança e agilizou o planejamento didático das aulas, mas deixou também uma lacuna: o conhecimento de conteúdo epistemológico. Por essa razão, a professora expressou suas percepções pessoais e sua análise foi superficial e curta em comparação com a dos conteúdos. Posteriormente a essa experiência, as novas hipermídias passaram a conter os saberes da comunidade e o conhecimento científico inerente, embora isso seja feito separadamente, em menus distintos. A ideia é que os estudantes interajam inicialmente com os saberes da comunidade e respondam às perguntas propostas realizando discussões e pesquisas em grupos, com a opção de acesso às informações científicas disponíveis. Nesse contexto, para dar autonomia aos professores envolvidos nas investigações em sala de aula, as estratégias adotadas foram: $1^{\text {a) }}$ dar acesso aos conteúdos por meio de "narrativas híbridas" e 2a) elaborar uma análise epistemológica dos saberes e disponibilizá-la na forma de textos de fácil leitura e entendimento. Para concretizar a primeira, foi necessário compreender previamente o conceito de hibridismo.

\section{Hibridismo/hibridização}

O hibridismo apresenta várias conceituações. Uma visão geral é a que se refere à combinação de duas partes genericamente distintas para produzir outras com novas características e aplicações. Nos anos de 1900, a palavra "híbrido" foi um termo científico importante no campo da biologia, mas já desde os anos 1800 esteve presente em um debate polêmico sobre as origens da humanidade. Nessa época, alguns atribuíam a esterilidade dos descendentes de cruzamentos animais à união de diferentes espécies e se isso fosse válido para o cruzamento entre as "raças" poderia servir como evidência de poligenismo. 
Muitas pessoas temiam esses cruzamentos e as palavras "miscigenação" e "amalgação" foram usadas para designar cruzamentos fecundos, enquanto "híbrido" foi usado para se referir à sucessão infértil. Esse fenômeno começou a ser estudado em plantas durante o século XVIII por Joseph Kölreuter e Charles Darwin dedicou um capítulo do livro $A$ Origem das Espécies ao hibridismo, enfatizando que a infertilidade não era uma regra interespécies e também poderia ocorrer dentro de uma mesma variedade, mas isso só foi compreendido posteriormente com o desenvolvimento da genética. O paradigma orgânico do século XIX se desenvolveu paralelamente ao do hibridismo, pressionando o crescimento conjunto (ou não) de entidades incompatíveis. Várias teorias foram propostas ao longo da história, mostrando o hibridismo tanto atraente - no sentido de mistura e transformação, como repugnante - no sentido de corrupção, impurificação, degradação e degeneração dos seres humanos. Historicamente, no entanto, as relações envolvendo linguagem e sexo foram fundamentais para o surgimento das chamadas formas "híbridas" (Young, 1995).

Esta ideia migrou também para outras áreas da ciência como, por exemplo, na proposição da teoria da hibridação dos orbitais atômicos para explicar a geometria de moléculas simples pelo químico Linus Pauling no ano de 1931. Também vem sendo utilizada em tecnologia: os veículos híbridos são uma promessa para economia de combustível e outras formas híbridas são conhecidas (fontes de alimentação híbrida, geradores híbridos, computadores híbridos, etc.). A partir do século XX, o hibridismo começou a ser usado também nas ciências humanas, particularmente em teoria crítica literária, nos estudos culturais, da comunicação e em antropologia (Lund, 2006, p. xi), com abordagens empíricas, metodológicas e críticas. Empiricamente denota um estado geral de "misturação" ou processo de mistura (Stam, 2000 citado em Lund, 2006, p. xii). Sua invocação metodológica sinaliza estudos atentos ao que "está entre" os espaços e práticas de produção cultural: aqueles que pensam sobre o que acontece à cultura na medida em que se move e que problematizam noções puristas. Criticamente, o hibridismo é visto como "alavanca desconstrutiva" ou maneira de reverter e deslocar discursos e retóricas autoritárias; mais do que uma mistura de elementos díspares, é usado para descrever ou influenciar movimentos nos quais as práticas culturais e sociais tradicionalmente consideradas como "menores" vem se infiltrar e impingir as mais "altas" (Lund, 2006, p. xii). É nesse nível que o hibridismo se torna explicitamente oposicional, um tipo de subversão que se tornou um conceito-chave ou construto relevante na teoria pós-colonial (Carter, 2004, p. 826).

Nas obras literárias, o hibridismo aparece como uma característica dos romances. Muitos romancistas de hoje e de antigamente escreveram "obsessivamente" sobre o cruzamento e a mistura de identidades, quer em termos de classe, gênero, cultura, raça ou linguagem. Os romances sempre enfatizaram formas de contato, interações transculturais e o desejo frequentemente sexual pelo outro ou com o estado de ser que Hanif Kureishi chamou originalmente de "an inbetween" ("um estar entre") (Young, 1985, p. 3). Em sua análise do romance, a hibridização foi o nome dado por Mikhail 
Bakhtin (1981) a um dispositivo estratégico utilizado para criar uma imagem que está "indissoluvelmente entrelaçada" à inter-relação dialogizada entre linguagens para compor um "tecido artístico unitário".

O que é uma hibridização? É uma mistura de duas linguagens sociais dentro dos limites de um único enunciado, um encontro dentro da arena de um enunciado, entre duas consciências linguísticas diferentes separadas uma da outra por uma época, por diferenciação social ou por algum outro fator. (Bakhtin, 1981, p. 358)

O local da construção híbrida no romance é o enunciado ou, mais propriamente, dois enunciados misturados por um único falante com "dois modos de falar", "dois estilos", "duas linguagens", "dois sistemas de crenças semânticas e axiológicas" nos limites de uma única frase. Sua "estrutura sintática absolutamente específica” também desempenha um papel importante. As linguagens "nunca podem existir completamente" dessa maneira, mas sentidas na "construção sintática da dupla voz híbrida" (Bakhtin, 1981, p. 361). Na hibridização deliberada, uma das linguagens age como "imagem" ou "iluminação" de outra consciência linguística, "com cada uma pertencente a um sistema diferente de linguagem". O aspecto fundamental desse tipo de hibridização é a sua intencionalidade, mas há também uma forma inconsciente - a hibridização orgânica, que está presente na vida e na evolução histórica de todas as linguagens: "a linguagem e todas as linguagens mudam historicamente principalmente por meio da hibridização, por meio de uma mistura de várias linguagens coexistentes (...)” (Bakhtin, 1981, p. 358, 359).

A hibridização de Bakhtin teve influência sobre o hibridismo cultural e histórico pós-colonial de Homi Bhabha, mas foi transformada por esse último em um movimento ativo de desafio e resistência a um poder cultural dominante (Young, 1995, p.23). Esse movimento foi originalmente descrito na análise de escritos culturais da época do colonialismo Britânico, particularmente associados à inserção do "Livro Inglês" - a Bíblia impressa, na Índia, África e Caribe coloniais (Bhabha, 1998a). A Bíblia foi introduzida nessas colônias e traduzida para alguns dialetos locais com a intenção de modificar as crenças religiosas da população. Os nativos reagiram reconhecendo seu valor e significados, mas também os modificaram, afastando a palavra de Deus do meio Inglês como movimento de resistência ou subversão à autoridade colonial. Como um sinal de diferença, o "Livro Inglês" produziu uma "repetição", onde a autoridade colonial foi reconhecida, mas também um "deslocamento", como forma de resistência (Bhabha, 1998a, p. 161). Essa "dupla inscrição" tornou o "Livro Inglês" não mais uma presença plena e nem a representação de uma essência, mas uma "presença parcial", "menor que um e duplo": um híbrido (p. 169).

No que me pareceu ser a fusão do hibridismo de Bhabha com a hibridização de Bakhtin, Robert Young propôs um modelo para as interações culturais:

A forma dupla do hibridismo de Bakhtin oferece, portanto, um modelo dialético particularmente significativo para a interação cultural: um híbrido orgânico, que tenderá para a fusão, em conflito com o hibridismo intencional, que autoriza uma atividade contestatória, um cenário politizado de diferenças culturais colocadas uma de 
encontro a outra dialogicamente. (Young, 1995, p. 22)

Nesse modelo, há uma duplicidade teórica e política na medida em que trabalha em duas direções: para fundir e criar uma nova forma e para dispersar, intervir, traduzir e transformar. Na primeira o hibridismo é uma junção ("força que une") que transforma a diferença em semelhança. Implica fazer com que duas coisas distintas se tornem uma só, mas com a possibilidade de revertê-las às suas posições originais. Também pode consistir em separar uma entidade singular em duas ou mais partes (segunda direção), em dividir um objeto singular em dois, transformando o que é semelhante em diferente, embora as partes possam ser reunidas novamente ao final. O hibridismo, assim, se movimenta em dois sentidos, "mas de uma forma que faz com que o mesmo não seja mais o mesmo, o diferente não mais simplesmente diferente" (Young, 1995, p. 26).

$\mathrm{Na}$ abordagem de Bakhtin, a hibridização aplicada à construção de "narrativas híbridas" apontou para uma operação de mistura entre as linguagens sociais da comunidade e da ciência e ao estabelecimento de relações semânticas internamente dialógicas de acordo com uma disposição sintática específica. O hibridismo de Bhabha, por sua vez, é mais complexo e tem conotação política na medida em que representa uma forma de desafio e resistência à dominação cultural, deslocando, deformando, distorcendo, invertendo estrategicamente esse processo por meio de uma dupla visão. Quando intencionalmente focalizado na escrita, implica na criação de um espaço de tradução que afirma e contesta, ao mesmo tempo, as identidades originais visando à construção de um novo objeto ou identidade.

\section{As narrativas híbridas elaboradas inicialmente para o sítio Ciência na Comunidade}

Uma narrativa é uma construção literária contendo alguns elementos particulares. Norris, Guilbert, Smith, Hakimelahi, e Phillips (2005) distinguiram os seguintes: eventos, narrador, sede pela narrativa, tempo, estrutura, agenciamento, proposta e leitor. Em resumo:

Na perspectiva teórica, um princípio em particular tem sido repetidamente anunciado nas discussões da literatura sobre narrativas e podem servir para emoldurar nossa discussão: "Nós podemos conceber o discurso narrativo no mínimo e de um modo geral como atos verbais que consistem em alguém dizendo a alguém que algo aconteceu" (Hernstein Smith, 1981, grifo do autor). Nesse princípio encontramos referências a um narrador (alguém dizendo), um leitor (alguém que está recebendo a mensagem na forma escrita), eventos (algo que aconteceu) e o tempo passado. Vamos considerar cada um desses elementos da narrativa e descrever também aspectos importantes enfatizados por outros teóricos: sede pela narrativa, estrutura, agenciamento e proposta (Norris et al., 2005, p. 538).

A sede pela narrativa é o desejo desperto de saber o que irá acontecer. Tipicamente, as narrativas têm princípio, meio e fim, existe um tempo relativo à trama dos eventos, $\mathrm{o}$ tempo do discurso e uma conexão entre os acontecimentos. Esses aspectos compreendem 
a sua estrutura. O agenciamento refere-se aos personagens ou atores envolvidos; é onde o aspecto humano sobressai. Comunicar conhecimentos, sentimentos, valores, crenças e ajudar a compreender o que se passa resumem a proposta.

Para elaborar as narrativas híbridas do sítio Ciência na Comunidade, inicialmente foram escolhidos os trabalhos relativos ao preparo do sabão de cinzas e do vinho de laranja. O primeiro envolveu uma pesquisa que teve início no ano de 1984 e foi aprofundada posteriormente. Envolveu interações com oito indivíduos de quatro comunidades distintas e a realização de três experiências escolares. A narrativa foi intitulada "As mulheres de Minas Gerais e o sabão de cinzas", com referência à procedência e ao gênero predominante das personagens. O segundo tema foi objeto de estudo de um projeto de extensão desenvolvido no ano de 2002, constituído por um ciclo de interações com uma família e a inserção mediada de seus saberes para uma sala de aula de química. Referese à narrativa "Seu Zé, Dona Ná e o vinho de laranja", conforme são conhecidos pela comunidade local. A primeira narrativa é composta por cinco textos com fotografias e contém também links de acesso a vídeos curtos. A segunda contém quatro textos e fotografias. Ambas podem ser acessadas no sítio Ciência na Comunidade no seguinte endereço: http://www.ufsj.edu.br/ciencianacomunidade.

Em termos metodológicos, as narrativas foram escritas inicialmente em sua versão não-híbrida, descrevendo somente os saberes da comunidade. As informações científicas foram associadas em seguida. $\mathrm{O}$ primeiro texto das duas narrativas traça uma breve história das pesquisas desenvolvidas. O segundo apresenta dados históricos relativos ao sabão de cinzas e ao vinho de laranja e suas relações com artefatos semelhantes produzidos em outras partes do mundo. Os textos seguintes descrevem as ações ou procedimentos e é onde a hibridização se concretiza efetivamente. A seguir, para ilustrar, apresento dois exemplos de enunciados híbridos, cada qual pertencente a uma das duas narrativas:

-As cinzas são compactadas no "barrilero" usando um soquete ou mesmo as mãos "pra ficá bem socadinho". Caso contrário, se não forem bem compactadas, se não "enfiá ela bem na vasia", deixar "bem socadinho", se "pô a cinza lá só e pô a água", a dicuada "não sai tamém não": "aquilo sai raliiiinho", torna-se diluída, pouco concentrada. Nas palavras de Dona Aparecida é "pra podê dá fortidão na dicuada", para aumentar a concentração da lixívia das cinzas. Isto porque "quanto mais forte", quanto maior for a concentração da dicuada, "mais rápido fáiz o sabão", maior será a velocidade da reação de saponificação.

-Ele [Seu Zé] disse que "ferve lá dentro do garrafão pra virá vinho", "solta um gáis de dentro do garrafão que bobuia igual quando ferve uma água pra fazê café”. Na fermentação produz-se o gás dióxido de carbono e "quando o tempo tá frio ferve mais divagá", com abaixamento da temperatura a atividade fermentativa diminui produzindo menor quantidade de gás. 


\section{As atividades propostas}

No projeto original do sítio Ciência na Comunidade havia a ideia de propor atividades para explorar as narrativas híbridas, tal como a exposição de enunciados híbridos na tela do computador onde os professores poderiam separar frases e palavras arrastando-as com o mouse e colocando-as em espaços de acordo com suas procedências, de um lado a linguagem da comunidade e de outro a da ciência. Essa ideia foi estimulada pela visão dinâmica de Robert Young (1995) sobre o hibridismo e colocada em execução na proposição de oito atividades: duas envolvem o arraste de palavras e frases de textos híbridos para locais específicos; em outras duas propõe-se a associação semântica de enunciados dos dois contextos e a construção e o desmembramento de textos híbridos podem ser realizados nas quatro atividades seguintes. Na verdade, há 11 atividades propostas no sítio: a nona se refere a um jogo com imagens de materiais usados nas práticas da comunidade e em laboratórios científicos e as atividades 10 e 11 envolvem afirmativas sobre a ciência escolar e a respeito da natureza dos saberes da comunidade e da ciência, respectivamente. Em sua maioria, essas afirmações foram extraídas da literatura e visam provocar reflexões em professores e saber suas opiniões a respeito: se concordam, discordam, em que grau concordam ou discordam ou se não sabem dizer. Isso pode ser feito marcando uma entre cinco alternativas em formulários ou preenchendo campos específicos e enviando as respostas on-line. São 46 afirmativas na atividade 10 e 49 na atividade 11. Esse tipo de questionário foi observado em instrumentos de pesquisa cujos itens passaram por processos de validação por pares; suas referências são indicadas no sítio Ciência na Comunidade na aba Fundamentos teóricos. Alguns itens são de autoria própria, como, por exemplo: - Para incluir os saberes da comunidade nas aulas os professores precisam ter conhecimento dos saberes científicos inerentes (extraído de Adams, 2012 e Pomeroy, 1994); - Para lidar com diferentes modos de conhecer nas aulas é fundamental que os professores tenham conhecimentos sobre a natureza da ciência (extraído do debate publicado em Science Education).

\section{A análise epistemológica organizada em cinco textos}

A análise epistemológica dos saberes expressos nas narrativas híbridas foi organizada em cinco eixos/textos: os saberes e seus contextos, linguagens, práticas, teorias e representações. Esse conjunto constitui o conhecimento de conteúdo epistemológico elaborado, que pode ser acessado na aba Natureza dos Saberes do sítio Ciência na Comunidade. Para sua construção, inicialmente foram revisitadas algumas publicações do debate estabelecido na revista Science Education, particularmente aquelas que enfatizaram aspectos filosóficos e sobre a natureza da ciência. Estes aspectos também foram analisados em outras publicações. Em relação aos saberes locais, foram utilizados textos de antropólogos. As referências usadas são citadas nos textos disponíveis no sítio Ciência na Comunidade. Um problema foi a escolha de um referencial epistemológico que permitisse realizar uma análise comparativa que não prejudicasse ou subjugasse os saberes da comunidade em relação aos da ciência, conforme observado no debate da 
revista Science Education. A análise de Van Eijck e Roth (2007) sugeriu uma epistemologia que pode ser considerada justa por evitar os problemas epistemológicos dos dois lados do debate entre universalistas e multiculturalistas. $\mathrm{O}$ primeiro problema diz respeito à relação entre conhecimento e realidade. Para avaliar a validade dos conhecimentos, os dois quadros de referência partiram dessa relação, mas com diferentes constituintes. Entre os universalistas existe a noção realista de que a validade do conhecimento é inerente à plausibilidade da relação entre conhecimento e realidade material. $\mathrm{O}$ conhecimento científico satisfaz esse requisito porque constrói seus conceitos sobre essa realidade. De outro lado, subjacente ao multiculturalismo, existe a noção relativista de que a validade do conhecimento é inerente à plausibilidade da relação entre conhecimento e realidade cultural. Assim, nessa última, o conhecimento ecológico tradicional indígena é tão válido quanto o conhecimento científico. Desse modo, os conhecimentos são vistos segundo diferentes epistemologias, o que torna impossível reduzi-los um ao outro; são "incomensuráveis", no dizer de Van Eijck e Roth (2007, p. 931). Para resolver o impasse, tais autores sugeriram vincular a realidade física e cultural simultaneamente na análise.

O segundo problema refere-se ao uso da noção de "verdade" como medida para validação dos conhecimentos, cujo conceito é problemático na medida em que depende de determinado "regime de verdade" (Foucault, 1979 citado em Van Eijck, \& Roth, 2007, p. 931) - a forma de pensar imposta pelas associações, instituições ou sociedades de discurso que determinam o que é verdadeiro ou falso. Ao invés de estabelecer essa relação, sugeriram adotar a "utilidade do conhecimento" como dimensão epistêmica, considerando que os conhecimentos adquirem suas finalidades em contextos específicos. Em outras palavras, conhecimento e contexto são mutuamente constitutivos. O terceiro problema apontado é a visão estática, singular e homogênea dos debatedores sobre conhecimento e cultura, que não considera as trocas, relações e o dinamismo dos sujeitos e suas culturas:

Esta noção arrebata precisamente a identidade cultural dos povos, povos indígenas inclusive, como uma entidade atual, dinâmica, que fornece a identidade real por sua vivência contínua (egoexisto) em oposição a uma entidade enraizada em uma fundação pura, estática e imutável (nunca-existente) proveniente de um passado desconhecido (não vivido) (res cogitans). (Van Eijck, \& Roth, 2007, p. 932)

Esses autores utilizaram a teoria histórico-cultural da atividade como epistemologia para realizar uma análise dos conhecimentos indígena e científico, dando continuidade ao debate no periódico Science Education. Nessa teoria, o conhecimento é sempre conhecimento em contexto e decorre de ações onde as necessidades humanas são centrais: "não há tal coisa como conhecimento que faça sentido independente da atividade humana” (Henry, 2003 citado emVan Eijck, \& Roth, 2007, p. 933). Assim, os saberes das narrativas híbridas foram, de início, vinculados às culturas e meios sociais de origem e desenvolvimento e às suas finalidades: os saberes sobre o sabão de cinzas e o vinho de laranja relacionam-se à produção desses materiais para fins específicos e os saberes científicos buscam explicações para os fenômenos. Para aprofundar essa análise 
particular, o leitor poderá consultar o texto Os saberes e seus contextos na aba "Natureza dos Saberes" do sítio Ciência na Comunidade.

Embora Van Eijck e Roth (2007) tenham utilizado uma referência justa para realizar a análise epistemológica, eles também enfatizaram uma tendência comum no debate publicado na revista Science Education: o estabelecimento de uma "ontologia da diferença” (p. 933). Essa abordagem é problemática no presente estudo, porque reforça as oposições binárias entre os saberes e contraria a perspectiva do hibridismo póscolonial, onde as fronteiras já não são mais tão nítidas ou se tornaram "turvas" (Carter, 2004; Mckinley, 2007). Em minha percepção, as diferenças tendem a separar os saberes enquanto que as semelhanças os aproximam, o que me sugeriu estabelecer também uma “ontologia da semelhança”. No texto Os saberes e suas práticas, por exemplo, é mencionado que as atividades realizadas na comunidade e em laboratórios científicos apresentam as seguintes semelhanças: extraem substâncias, separam resíduos, dissolvem materiais, recolhem gases, realizam testes de qualidade, observam e controlam fenômenos naturais e há criatividade nas duas formas. Outra característica da análise epistemológica realizada é o tratamento conjunto dos saberes, alternando entre os seus contextos, linguagens, práticas e sistemas de explicação, aprofundando peculiaridades e o que é exclusivo de cada um. Nessa análise, um destaque é a justificativa de filósofos da ciência (Ladrière, 1977; Loving, 1995; Wolpert, 1994) para considerar os saberes da comunidade como sendo "tecnologias" e não "ciência", principalmente por suas diferentes motivações e aos processos de teorização que são únicos desta última. Para aprofundar esse aspecto, ver o texto Os saberes e suas teorias.

\section{Considerações finais}

O objetivo deste artigo foi descrever os antecedentes, fundamentos e a construção de um conjunto de recursos disponibilizados inicialmente no sítio Ciência na Comunidade, um ambiente criado na internet para compartilhar experiências de interação com saberes culturais locais. O ponto de partida foi a revisão da literatura relativa à inserção de outros modos de conhecer na educação em ciências e a sua convergência com resultados de experiências em salas de aula, na direção de oferecer conhecimento de conteúdo epistemológico para professores. Para fazer isto, foram elaboradas narrativas híbridas, atividades e textos sobre a natureza dos saberes da comunidade e da ciência e foi feita a transferência desse conjunto para a internet. Para verificar os efeitos desses recursos, há dois questionários elaborados para levantamento de dados no sítio Ciência na Comunidade, os quais serão descritos em publicações futuras junto aos resultados observados entre um grupo inicial de participantes.

As narrativas híbridas elaboradas contêm enunciados que misturam as linguagens sociais da comunidade e da ciência para constituir uma inter-relação semântica dialogizada. Nesta construção, Bakhtin (1981, p. 359) mencionou que uma linguagem age como "imagem" ou "iluminação" da outra (em nosso caso, a linguagem da ciência), mas, tal como Faraco (2009), considero que essas linguagens se apoiam mutuamente, 
se interiluminam ao configurarem diferentes modos de conhecer colocados em relação dialógica. Na perspectiva do hibridismo de Bhabha (1998), cada posição é sempre um processo de tradução e transferência de significados, no qual cada objeto se desloca em relação ao outro e é deslocado neste ato. As atividades envolvendo a associação e separação de palavras e frases exemplificam essas características, mas o que mais se destaca nessa construção é que no texto híbrido a autoridade entra em crise porque nele não é possível existir uma voz autoritária. Ela não pode existir como tal devido à sua singularidade e incapacidade de ser bivocal (Young, 1995).

Os enunciados das narrativas híbridas possuem também uma construção sintática que apresenta diferentes possibilidades: ora trazendo inicialmente a linguagem da comunidade e depois a da ciência, ora invertendo essa ordem e ora alternando-os dinamicamente (para perceber isto, o leitor deve observar a ordenação variada das linguagens nos enunciados híbridos das narrativas no sítio Ciência na Comunidade). Isto foi alcançado por meio de um "quebra-cabeça", onde as palavras e frases de cada contexto foram posicionadas e reposicionadas em diferentes locais dos enunciados até encontrar as melhores formas (ou encaixes) para cada caso. Outra característica é a iteratividade ou repetição de enunciados híbridos ao longo das narrativas. Isto não se deveu exclusivamente ao desenrolar da trama de eventos/fenômenos, mas ao objetivo de incitar a reflexão. Bhabha (1994) mencionou que o pensamento reflexivo emerge nos interstícios culturais segundo um processo constante de repetição entre ir além (se referindo ao hibridismo) e retornar à condição de separação/exclusão de modo a transformá-la.

Em experiências de pesquisa, o hibridismo vem sendo dado como sinônimo de "terceiro espaço" para designar a "fusão ou integração de saberes e discursos" (Moje, Ciechanowski, Kramer, Ellis, Carrillo, \& Collazzo, 2004, p. 41) e para nomear uma "atividade expandida" capaz de estabelecer "zonas ricas de colaboração e aprendizagem" ou "zonas de desenvolvimento proximal" com "potencial transformativo" (Gutierrés, Baquedano-López, \& Tejeda, 1999, p. 286, 287). No "terceiro espaço", categorias aparentemente distintas, opostas ou descontínuas trabalham juntas para gerar novos conhecimentos, discursos, identidades e formas de letramento. Na educação em ciências, alguns estudos vêm utilizando o hibridismo como referência para investigar identidades de professores e alunos e como forma de promover interações curriculares com o conhecimento indígena (Mckinley, \& Gan, 2014). Até o presente, não tenho conhecimento de outras experiências envolvendo a construção e utilização de textos híbridos na educação em ciências. A mistura de linguagens não é uma característica comum das formas de letramento dessa disciplina ou da formação de professores. A literatura revisada também não demonstrou experiências deste tipo e uma tendência é observar visões estáticas, singulares e homogêneas de outros modos de conhecer, tal como foi observado por Van Eijck e Roth (2007) no debate entre universalistas e multiculturalistas na revista Science Education. É preciso lembrar, contudo, o aspecto intencional desta construção aliado à expectativa de que os professores percebam 
a possibilidade de criação de "terceiros espaços" na interação com outros modos de conhecer na educação em ciências. Embora ainda não haja clareza quanto às contribuições desta atividade para a aprendizagem e a formação docente, é possível afirmar que se trata de uma forma de letramento que dá acesso simultâneo a saberes da comunidade e da ciência e a aquisição desses conhecimentos foi uma recomendação de Adams (2012) e de George (1992) aos professores, mas que não teria sido possível sem o apoio deste pesquisador, já que os professores não têm tempo, normalmente não dispõem de conhecimento ou entendimento sobre o conhecimento cultural e os livros didáticos de ciências também não ajudam nesse sentido (Stephens, 2003).

Bakhtin mencionou que a hibridização nos romances consiste em um "jogo com linguagens sociais artisticamente profundo" que "exige enorme esforço" (Bakhtin, 1981, p. 366, 367) e é certo que isto também possa ser afirmado para o trabalho de construção das narrativas híbridas deste estudo, mas devem ser consideradas também as investigações etnográficas junto à comunidade e a análise do discurso dos informantes como ferramentas que permitiram construir as narrativas cuja densidade é difícil de ser observada na literatura (ver, por exemplo, as descrições do conhecimento indígena sobre a migração do salmão em Cobern, \& Loving, 2001 e em Van Eijck, \& Roth, 2007). Neste sentido, o suporte da internet foi importante para que os saberes fossem representados mais adequadamente, embora este processo seja sempre parcial e incompleto.

A análise epistemológica realizada neste estudo procurou vincular a realidade física e cultural, identificar as finalidades dos saberes e associá-los aos seus contextos, estabelecendo uma ontologia de semelhanças e diferenças coerente com o hibridismo pós-colonial. A vinculação com seus contextos de desenvolvimento esteve presente nas narrativas híbridas e na análise epistemológica realizada e levaram à reflexão de que se esta é uma condição essencial para o tratamento adequado de outros modos de conhecer nas aulas de ciências, o mesmo pode ser dito em relação aos saberes científicos ensinados na escola. Isto também foi considerado como uma atitude de respeito pelas autoras abaixo:

Se, por exemplo, a maneira que ensinamos ciência nas escolas silencia as características que circundam a "produção do fato científico", então a maneira como os estudantes aprendem a valorizar um ao outro como usuários e produtores de ciência também é silenciada (Slaton, \& Barton, 2012, p. 524).

No presente estudo, a análise epistemológica dos saberes e práticas da comunidade e da ciência foi organizada e disponibilizada em cinco textos no sítio Ciência na Comunidade. A análise da natureza da ciência realizada difere daquela normalmente observada em publicações da área, as quais tendem a investigar contextos autênticos de atividade científica, ou seja, enfatizam a "Big Science" (Abd-El-Khalic, 2012). Todavia, a literatura vem mostrando que os professores têm dificuldades de realizar abordagens epistemológicas em sala de aula e alguns especialistas vem procurando resolver esse problema com o desenvolvimento de cursos de formação continuada por longo tempo (Lederman, \& Lederman, 2012). A análise epistemológica descrita neste artigo difere 
por ser do tipo relacional e por expressar também conteúdos epistemológicos sobre os saberes e práticas da comunidade. Os textos foram submetidos à apreciação por dois especialistas e foram considerados textos que tratam da natureza da ciência. Estão disponíveis na internet e no formato PDF, em língua Portuguesa e Inglesa, para os interessados em aprofundar ou adquirir conhecimento de conteúdo epistemológico de saberes culturais locais e científicos e para subsidiar o desenvolvimento de futuras experiências em salas de aula da educação básica e sobre a formação docente.

\section{Agradecimentos}

Este estudo foi realizado no âmbito de um Estágio Pós-Doutoral no exterior com apoio da Coordenação de Aperfeiçoamento de Pessoal de Nível Superior (CAPES - Processo BEX No1992/14-7). Agradeço ao apoio desta agência e aos seus funcionários, bem como ao pessoal do George C. Mallinson Institute for Science Education/Western Michigan University/USA, pelo notável acolhimento e suporte. Gratidão especial ao Dr. William W. Cobern (Diretor do MISE/WMU/EUA), por seu notável estímulo e assistência, e ao Dr. Norman G. Lederman, do College of Science/Illinois Institute of Technology/EUA, por sua pronta atenção e crítica. Agradeço também à Rosária Justi, editora desta revista, por suas valiosas sugestões e revisão deste manuscrito.

\section{Referências}

Abd El-Khalic, F. (2012). Nature of science in science education: toward a coherent framework for synergistic research and development. In B. J. Fraser, K. T. Tobin, \& C. J. McRobbie (Orgs.), Second International Handbook of Science Education (pp. 10411060). New York, NY: Springer.

Achutti, L. E. R. (2003). Fotos e palavras, do campo aos livros. Revista Studium, 12. Recuperado de http://www.studium.iar.unicamp.br/12/1.html.

Adams, J. D. (2012). Community Science: capitalizing on local ways of enacting science in science education. In B. J. Fraser, K. T. Tobin, \& C. J. McRobbie (Orgs.), Second International Handbook of Science Education (pp. 1163-1177). New York, NY: Springer.

Aikenhead, G. (1996). Science Education: border crossing into the subculture of science. Studies in Science Education, 27, 1-52.

Antweiler, C. (1998). Local knowledge and local knowing: an anthropological analysis of contested "cultural products" in the context of development. Anthropos, 93, 469-494.

Atwater, M. M., \& Riley, J. P. (1993). Multicultural science education: perspectives, definitions, and research agenda. Science Education, 77(6), 661-668.

Baptista, G. C. S., \& El-Hani, C. N. (2009). The contribution of ethnobiology to the construction of a dialogue between ways of knowing: A case study in a Brazilian public high school. Science \& Education, 18, 503-520. 
Baptista, G. C. S., Vargas-Clavijo, M., \& Neto, E. M. C. (Orgs.). (2014). A etnobiologia na educação ibero-americana: compreensão holística e pluricultural da biologia. Feira de Santana/Bahia: UEFS Editora.

Bakhtin, M.M. (1981). The dialogic imagination: four essays. Austin: University of Texas Press.

Bakhtin, M. M. (1986). Speech genres and other late essays. Austin: University of Texas Press.

Bakhtin, M. (2004). Marxismo e filosofia da linguagem. 11. ed. São Paulo: Hucitec.

Bhabha, H. K. (1998a). O local da cultura. Belo Horizonte: Editora da UFMG.

Bhabha, H. (1998b). The commitment to theory. New Formations, 5, 5-23.

Brandão, C. R. (Org.). (1982). Pesquisa participante (2. ed.). São Paulo: Brasiliense.

Brandão, C. R. (Org.). (1987). Repensando a pesquisa participante (3. ed.). São Paulo: Brasiliense.

Brown-Acquaye, H. A. (2001). Each is necessary and none is redundant: the need for science in developing countries. Science Education, 85(1), 68-70.

Carter, L. (2004). Thinking differently about cultural diversity: using postcolonial theory to (re)read science education. Science Education, 88(6), 819-836.

Cavaglier, M. C. S., \& Messeder, J. C. (2014). Plantas medicinais no ensino de química e biologia: propostas interdisciplinares na educação de jovens e adultos. Revista Brasileira de Pesquisa em Educação em Ciências, 14(1), 55-71.

Chassot, A. I. (1990). A Educação no Ensino da Química. Ijuí: Unijuí, 1990.

Chassot, A. I. (2001). Alfabetização Científica: questões e desafios para a educação. Ijuí: Unijuí.

Chassot, A. I. (2008a). Fazendo educação em ciências em um curso de pedagogia com inclusão de saberes populares no currículo. Química Nova na Escola, 27, 9-12.

Chassot, A. I. (2008b). Sete Escritos Sobre Educação e Ciência. São Paulo: Cortez.

Chinn, P. W. U. (2007). Decolonizing methodologies and indigenous knowledge: the role of culture, place and personal experience in professional development. Journal of Research in Science Teaching, 44(9), 1247-1268.

Chinn, P. W. U. (2012). Developing teachers' place-based and culture-based pedagogical content knowledge and agency. In B. J. Fraser, K. G. Tobin, \& C. J. McRobbie (Eds.), Second International Handbook of Science Education (pp. 323-334). New York, NY: Springer.

Clifford, J. (1998). A Experiência Etnográfica: antropologia e literatura no século XX. Rio de Janeiro: Editora UFRJ. 
Cobern, W. W., \& Loving, C. C. (2001). Defining "Science" in a multicultural world: implications for science education. Science Education, 85(1), 50-67.

Corsiglia, J, \& Snively, G. (2001). Rejoinder: Infusing Indigenous Science into Western Modern Science for a sustainable future. Science Education, 85(1), 82-86.

D’Ambrosio, U. (1998). Etnomatemática. 5. ed. São Paulo, SP/Brazil: Ática.

D’Olne Campos, M. (2002). Etnociência ou etnografia de saberes, técnicas e práticas? In M. C. D. Amoroso, L. C. Ming, \& S. P. Silva (Orgs.), Métodos de coleta e análise de dados em etnobiologia, etnoecologia e disciplinas correlatas (pp. 47-91). Rio Claro, SP: Coordenadoria da área de Ciências Biológicas-Gabinete do Reitor-UNESP/CNPq.

Faraco, C. A. (2009). Linguagens e diálogos: as ideias linguísticas do Círculo de Bakhtin. São Paulo, SP/Brazil: Parábola Editorial.

Foucault, M. (1986). A Arqueologia do Saber (2. ed.). Rio de Janeiro, RJ: Forense Universitária.

France, C. (2000). Antropologia fílmica: uma gênese difícil, mas promissora. In: France, C. (Org.). Do filme etnográfico à Antropologia fílmica. Campinas, SP: Editora da Unicamp. Francisco, Z. L. (2004). O Ensino de Química em Moçambique e os saberes culturais locais (Tese de doutorado). Pontifícia Universidade Católica, São Paulo.

Francisco Junior, W. E. J., Yamashita, M., \& Martines, E. A. L. M. (2013). Saberes regionais amazônicos: do garimpo de ouro no Rio Madeira (RO) às possibilidades de Inter-relação em aulas de Química/Ciências. Química Nova na Escola, 35(4), 228-236.

Geertz, C. (1973). The interpretation of cultures. New York: Basic Books.

George, J. (1988). The role of native technology in science education in developing countries: a Caribbean perspective. School Science Review, 69(249), 815-821.

George, J. (1992). Science teachers as innovators using indigenous resources. International Journal of Science Education, 14(1), 95-109.

George, J. (1999). World view analysis of knowledge in a rural village: implications for science education. Science Education, 83(1), 77-95.

Gondim, M. S. C., \& Mol, G. S. (2008). Saberes populares e ensino de ciências: possibilidades para um trabalho interdisciplinar. Química Nova na Escola, São Paulo, 30, 3-9.

Grills, S. (1998). Doing ethnographic research: fieldwork settings. Thousand Oaks: SAGE Publications.

Gutierrés, K. D, Baquedano-López, P., \& Tejeda, C. (1999). Rethinking diversity: hybridity and hybrid language practices in the third space. Mind, Culture, and Activity, 6(4), 286-303. 
Haden, J. (1973). Iron and education in Uganda. Education in Chemistry, 10(2), 49-51. Hodson, D. (1993). In search of a rationale for multicultural science education. Science Education, 77(6), 685-711.

Ladrière, J. (1977). The challenge presented to cultures by science and technology. Paris: UNESCO.

Leal, R. C., \& Moita Neto, J. M. (2013). Amido: Entre a Ciência e a Cultura. Química Nova na Escola, São Paulo, 35(2), 75-78.

Lederman, N. G., \& Lederman, J. S. (2012). Nature of scientific knowledge and scientific inquiry: building instructional capacity through professional development. In Fraser, B. J., Tobin, K. G., \& McRobbie, C. J. (Eds.). Second International Handbook of Science Education (pp. 335-359). New York, NY: Springer.

Lévi-Straus, C. (1994). Saudades do Brasil. São Paulo, SP/Brazil: Companhia das Letras. Loving, C. C. (1995). Comment on "Multiculturalism, Universalism, and Science Education". Science Education, 79(3), 341-348.

Lund, J. (2006). The impure imagination: toward a critical hibridity on Latin America writing. Minneapolis, MN/Unites States: University of Minnesota Press.

Maddock, M. N. (1981). Science Education: An Anthropological Viewpoint. Studies in Science Education, 8(1), 1-26.

Malinowski, B. (1984). Os Argonautas do Pacífico Ocidental: um relato do empreendimento e da aventura dos nativos nos arquipélagos da Nova Guiné Melanésia. São Paulo: Abril Cultural.

Mckinley, E. (2001). Cultural diversity: masking power with innocence. Science Education, 85(1), 74-76.

Mckinley, E. (2007). Postcolonialism, indigenous students, and science education. In S. K. Abell, \& N. G. Lederman (Eds.). Handbook of research on science education (pp. 199-226). Mahwah, NJ: Lawrence Erlbaum.

Mckinley, E., \& Gan, M. J. S. (2014). Culturally responsive science education for indigenous and ethnic minority students. In N. G. Lederman, \& S. K. Abell (Eds.), Handbook of Research on Science Education, Volume II (pp. 284-300). New York, NY: Routledge.

Mckinley, E., \& Stewart, G. (2012). Out of place: indigenous knowledge in the science curriculum. In B. J. Fraser, K. T. Tobin, \& C. J. McRobbie (Eds.). Second International Handbook of Science Education (pp. 541-554). New York, NY: Springer.

Medeiros, A., \& Medeiros, C. (2002). Os raios no imaginário popular. Revista Brasileira de Pesquisa em Educação em Ciências, 2(3), 84-96. 
Ministério da Educação. (2013). Diretrizes Curriculares Nacionais para a Educação Básica. Recuperado de http://portal.mec.gov.br/index.php?option=com_ docman\&view=download\&alias=15548-d-c-n-educacao-basica-novapdf\&Itemid=30192

Moje, E. B, Ciechanowski, K. M, Kramer, K., Ellis, L., Carrillo, R., \& Collazzo, T. (2004). Working toward third space in content area literacy: an exam of everyday funds of knowledge and discourse. Reading Research Quarterly, 39(1), 38-70.

Montellano, B. R. O. (2001). Multicultural science: who benefits? Science Education, 85(1), 77-79.

Nascimento, F., Fernandes, H. L., \& Mendonça, V. M. (2010). O Ensino de Ciências no Brasil: História, Formação de Professores e Desafios Atuais. Revista HISTEDBR On-line, 10(39), 225-249.

Norris, S. P., Guilbert, S. M., Smith, M. L., Hakimelahi, S., \& Phillips, L. M. A. (2005). Theoretical Framework for Narrative Explanation in Science. Science Education, 89(4), $535-563$.

Ogawa, M. (1995). Science education in a multiscience perspective. Science Education, 79(5), 583-593.

Pinheiro, P. C., Mendes, L. A., Maurício, L. A., Monteiro, M. B. A., Monteiro, R. A., \& Colli, G. (1985). O fabrico do sabão de cinzas e suas implicações para o ensino de ciências no nível elementar. In Resumos do $1^{\circ}$ Congresso De Educação Através da Química (p. 4-5). Niterói, RJ/Brasil: Universidade Federal Fluminense/Sociedade Brasileira de Química.

Pinheiro, P. C., Felício, E. C., \& Monteiro, R. (1987). The science teaching and the popular technologies: popular technologies of making soap - the ash soap. In Abstracts da Ninth International Conference on Chemical Education (p. 339). São Paulo, SP/Brasil: Universidade de São Paulo/IUPAC.

Pinheiro, P. C., \& Felício, E. C. A. (1988). Sobre uma atividade com o sabão de cinzas na escola de $1^{\circ}$ grau. In Resumos da 40a Reunião Anual da Sociedade Brasileira para o Progresso da Ciência (p. 594). São Paulo, SP/Brasil: SBPC.

Pinheiro, P. C., \& Gomes, A. S. (2000). A produção artesanal de tijolos: um saber patrimonial estudado nas aulas de ciências de uma sala multisseriada. In Resumos da $23^{a}$ Reunião Anual da Sociedade Brasileira de Química (p. ED005). Poços de Caldas, MG/Brasil: SBQ.

Pinheiro, P. C. (2007). A interação de uma sala de aula de química de nível médio com o hipermídia etnográfico sobre o sabão de cinzas vista através de uma abordagem sócio(trans) cultural de pesquisa (Tese de doutorado). Faculdade de Educação, Universidade de São Paulo, São Paulo. 
Pinheiro, P. C., \& Giordan, M. (2008). The interaction between a Brazilian chemistry classroom and the ash soap makers' cultural knowledge mediated by an ethnographic hypermedia narrative. In Abstracts do Second International Society for Cultural and Activity Research Congress. San Diego, Cf/United States: UCSD/ISCAR.

Pinheiro, P. C., \& Giordan, M. (2010). O preparo do sabão de cinzas em Minas Gerais, Brasil: do status de etnociência à sua mediação para a sala de aula utilizando um sistema hipermídia etnográfico. Investigações em Ensino de Ciências, 15(2), 355-383.

Pomeroy, D. (1994). Science education and cultural diversity: mapping the field. Studies in Science Education, 24(1), 49-73.

Posey, D. (1986). Etnobiologia: teoria e prática. In: Ribeiro, D. (Org.). Suma Etnológica Brasileira (pp. 15-25). Petrópolis: Vozes/FINEP.

Resende, D. R., Castro, R. A., \& Pinheiro, P. C. (2010). O saber popular nas aulas de química: relato de experiência envolvendo a produção do vinho de laranja e sua interpretação no ensino médio. Química Nova na Escola, 32(3), 151-160.

Etnomatemática. (2001). Scientific American Brasil, 11, São Paulo: Duetto.

Etnoastronomia. (2006). Scientific American Brasil, 14. São Paulo: Duetto.

Silva, J. R. S. (2003). O conceito de proporção no contexto da construção civil a partir da mistura argamassa do tipo: cimento $\mathrm{x}$ areia. Revista Brasileira de Pesquisa em Educação em Ciências, 3(1), 58-69.

Silva, P. B., Aguiar, L. H., \& Medeiros, C. F. (2000). O papel do professor na produção de medicamentos fitoterápicos. Química Nova na Escola, 11, 19-23.

Silveira, K. P., \& Mortimer, E. F. (2011). Tradição Maxacali e conhecimento científico: diferentes perspectivas para o conceito de transformação. Revista Brasileira de Pesquisa em Educação em Ciências, 11(3), 9-33.

Slaton, A., \& Barton, A. C. (2012). Respect and science learning. In B. J. Fraser, K. T. Tobin, \& C. J. McRobbie (Eds.), Second International Handbook of Science Education (pp. 513-525). New York, NY: Springer.

Snively, G., \& Corsiglia, J. (2001). Discovering indigenous Science: Implications for Science Education. Science Education, 85(1), 6-34.

Snively, G, \& Corsiglia, J. (2005). Response to Carter's postmodern, postcolonial analysis of Snively and Corsiglia’s (2000) article "Discovering Science". Science Education, 89(6), 907-912.

Stanley, W. B., \& Brickhouse, N. W. (1994). Multiculturalism, universalism and science education. Science Education, 78(4), 387-398.

Stanley, W. B., \& Brickhouse, N. W. (2001a). Teaching sciences: the multicultural question revisited. Science Education, 85(1), 35-49. 
Stanley, W. B., \& Brickhouse, N. W. (2001b). Response to our critics. Science Education, 85(1), 87-88.

Stephens, S. (2003). Handbook for Culturally Responsive Science Curriculum. Fairbanks: Alaska Native Knowledge Network.

Van Eijck, M., \& Roth, W-M. (2007). Keeping the local local: recalibrating the status of science and traditional ecological knowledge (TEK) in education. Science Education, 91(6), 926-947.

Venquiaruto, L. D., Dallago, R. M., Vanzeto, J., \& Pino, J. C. D. (2011). Saberes populares fazendo-se saberes escolares: um estudo envolvendo a produção artesanal do pão. Química Nova na Escola, 33(3), 135-141.

Warren, D. M., Slikkerveer, L. J., \& Brokensha, D. (Eds.). (1995). The Cultural Dimension of Development: indigenous knowledge systems. London: Intermediate Technology Publications.

Wertsch, J. V. (1993). Voices of the Mind: a sociocultural approach to mediated action (4a ed.). Cambridge: Harvard University Press.

Wolpert, L. (1994). The unnatural nature of science. Cambridge: Harvard University Press.

Xavier, P. M. A., \& Flôr, C. C. C. (2015). Saberes populares e educação científica: um olhar a partir da literatura na área de ensino de ciências. Ensaio, 17(2), 308-328.

Young, R. J. C. (1995). Colonial desire: hybridity in theory, culture and race. London: Routledge.

\section{Paulo César Pinheiro}

(1) http://orcid.org/0000-0002-7752-3614 Universidade Federal de São João Del Rei

Departamento de Ciências Naturais São João Del Rei, Brasil pcpin@ufsj.edu.br

Submetido em 20 de Março 2016

Aceito em 11 de Janeiro 2017

Publicado em 30 de Abril de 2017 